\title{
A Tool to Assess and Compare Knowledge Mobilization Efforts of Faculties of Education, Research Brokering Organizations, Ministries of Education, and School Districts
}

\author{
Amanda Cooper \\ Queen's University
}

\begin{abstract}
There are few tools that exist to measure knowledge mobilization (KMb), the process of connecting research to policy and practice across diverse organizations and sectors. This article reports on a comparison of KMb efforts of 105 educational organizations: faculties of education $(N=21)$, research brokering organizations $(N=44)$, school districts $(N=14)$, and ministries of education $(N=26)$. This study used a tool that analyzed KMb efforts along two dimensions-research dissemination strategies (e.g., products, events, and networks) and research use indicators (e.g., different types of strategies, ease of use, accessibility, collaboration, and mission)—using data available on organizational websites. Findings show that research brokering organizations and faculties of education are producing stronger knowledge mobilization efforts than school districts and ministries of education; however, even faculties and research brokering organizations often have modest efforts. Most KMb efforts are product based, with network strategies usually being the weakest KMb strategy utilized.
\end{abstract}

Keywords: research use; K-12 education; knowledge mobilization

Amanda Cooper is an Assistant Professor of Educational Policy and Leadership in the Faculty of Education at Queen's University in Kingston, Ontario. She is the Principal Investigator of RIPPLE - Research Informing Policy, Practice and Leadership in Education (www.ripplenetwork.ca) - a program of research, training, and knowledge mobilization aimed at learning more about how knowledge brokering can increase research use and its impact in public service sectors by leveraging multi-stakeholder collaboration.

Email: amanda.cooper@queensu.ca 


\section{Context: A Global Call for Evidence-based Policy and Practice}

There is a global call to improve the integration of research evidence in policy and practice in public service sectors (Nutley, Walter, \& Davis, 2007), efforts called knowledge mobilization $(\mathrm{KMb})$ in education in Canada. The expectations around the use of research have changed markedly in recent years for all stakeholders. Policymakers in government are being pressured by the public to engage in evidence-based decision making and to be transparent about what sources of evidence inform their decisions (Burns \& Schuller, 2007). Researchers are expected to increase the use and impact of their work, and practitioners are under pressure to use research evidence and data to inform their daily professional work. Funders all over the world are also beginning to require researchers to include $\mathrm{KMb}$ plans and summarize the potential impact of their work (Tetroe et al., 2008). Practitioners in school districts, including educational leaders and teachers, are also being pressured to increase data use at virtually all levels (Brown, 2015; Finnigan \& Daly, 2014).

Research brokering organizations (RBOs) (e.g., intermediary, third party organizations that connect researchers, policymakers, and practitioners) have arisen to help address these gaps between research, policy, practice, and impact (Coburn \& Stein, 2010; Cooper, 2014a). I define RBOs in relation to two characteristics: 1) Target audience: RBOs connect research producers and research users (hence organizations that connect researchers to researchers only or practitioners to practitioners only are not RBOs by my definition); and 2) Mission statement: RBOs have explicit mission statements and/or mandates in relation to data use, research use and/or knowledge mobilization. While many organizations are involved in research brokering as one part of their organizational activities, RBOs primary function is connecting research producers and users in a particular area to increase $\mathrm{KMb}$. My previous work has developed a typology of RBOs that exist across Canada differentiated by funding sources and location in the system (for further description and examples of RBOs, please see Cooper, 2013); major categories of RBOs include governmental RBOs, For-profit RBOs, Not-for profit RBOs, and Membership RBOs (where members of a network actually fund the organization such as teachers' unions). Meyer (2010) describes the role of knowledge or research brokers in relation to building connections between researchers and different potential target audiences:

Brokering involves a range of different practices: the identification and localization of knowledge, the redistribution and dissemination of knowledge, and the rescaling and transformation of this knowledge. Brokering knowledge thus means far more than simply moving knowledge - it also means transforming knowledge... knowledge brokering is likely to look very different in the various brokering spaces...not least because the needs and expectations of the knowledge users might differ substantially. (p. 120)

Despite these new expectations for policymakers, researchers, practitioners, and research brokering organizations, very little is known about the levels of KMb efforts occurring across the education system (e.g., who is engaging in $\mathrm{KMb}$ efforts and what kinds of $\mathrm{KMb}$ activities are occurring for what audiences). For example:

- The scant literature that does exist indicates low levels of $\mathrm{KMb}$ efforts from universities (Sá, Li, \& Faubert, 2011; Wilson, Petticrew, Calnan, \& Nazareth, 2010);

- The literature indicates low levels of research use in policymaking (Landry, Amara, \& Lamary, 2001; Lavis, Lomas, Hamid, \& Sewankambo, 2006); 
- There are low levels of research use and uptake in practice environments (Cooper \& Levin, 2013; Cordingley, 2008); and

- There are some empirical studies suggesting that intermediary research brokering agencies can improve and facilitate research use across research, practice, and policy organizations (Coburn \& Stein, 2010; Cooper, 2014a).

Given these limitations it is also important to note that, until recently, there was no tool to measure KMb activities across different kinds of organizations and sectors (Qi \& Levin, 2013). In this study, I apply the tool created by Qi and Levin (2013) to evaluate KMb efforts of 105 educational organizations in order to answer the following research question: How do the $\mathrm{KMb}$ efforts of faculties of education, ministries of education, research brokering organizations, and school districts in Canada compare?

\section{Conceptualizing KMb From a Whole System Perspective}

This study conceptualizes $\mathrm{KMb}$ as systemic efforts to increase research use in policy and practice, and involves many different kinds of organizations involved in the education sector. This whole-system perspective (Figure 1) includes policymaking, research production, research mediation, and research use, all of which are increasingly mediated by websites, online platforms, and social media tools being utilized for innovation and engagement.

\section{Knowledge Mobilization Occurs Across 4 Domains}

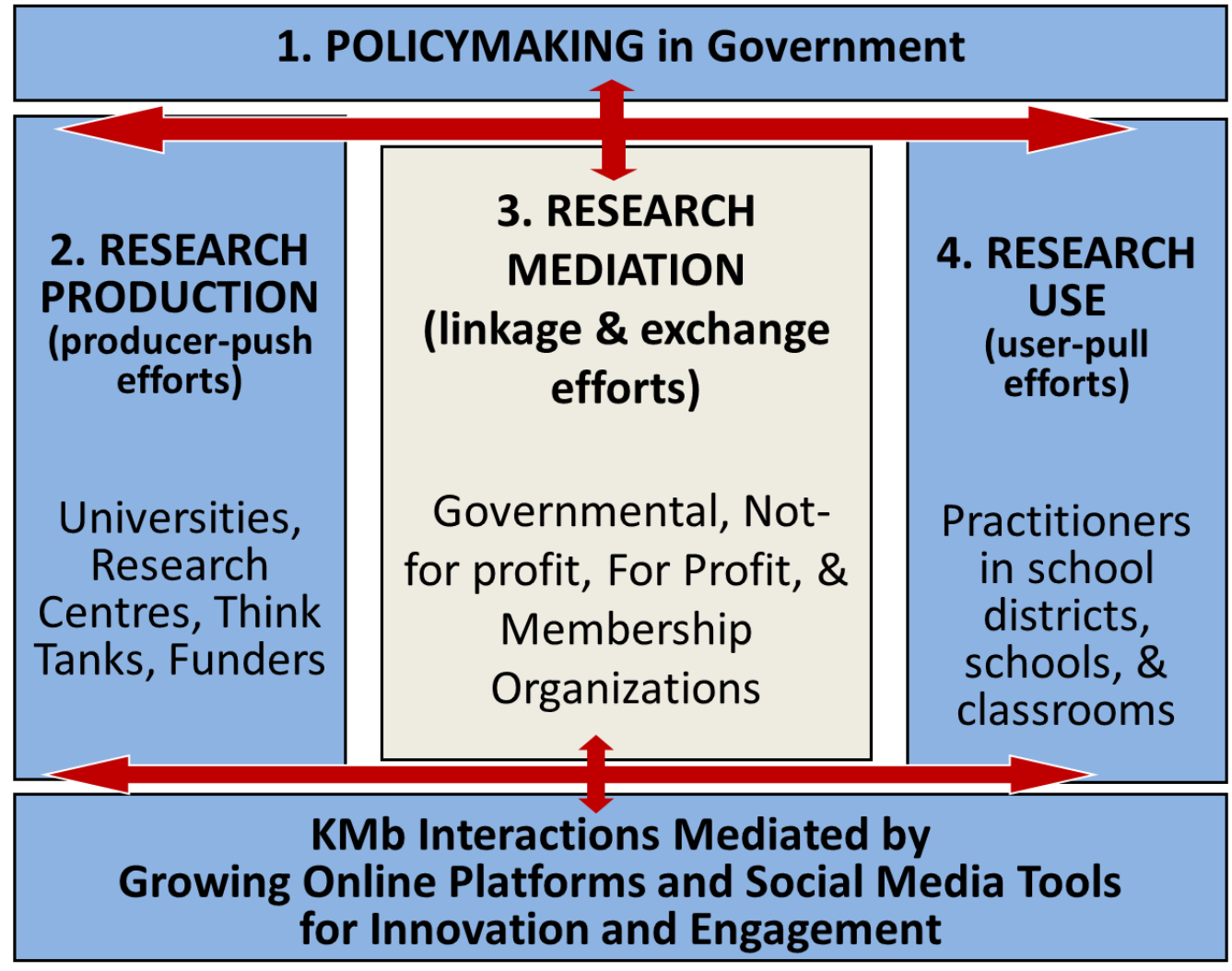

Figure 1. Knowledge Mobilization from a Whole-System Perspective (KMb/WSP) model. 
This model entitled "Knowledge Mobilization from a Whole-System Perspective" (KMb/ WSP) is adapted from Levin (2004); however, it separates the policymaking context from the practitioner context to address the very different purposes, types of work, and time frames for decision making of these two distinct groups, which often require different types of training and information that cater to their specific needs. Additionally, the conceptualization of KMb, which informs this study, acknowledges the changing nature of $\mathrm{KMb}$ efforts as they are increasingly mediated through online platforms such as websites and online communities as well as through social media outlets such as Twitter and Facebook (See Cooper 2014b for data on how RBOs are engaging with online dissemination and social media). My conceptualization of KMb in Figure 1 integrates Lavis et al.'s (2006) research utilization models with Levin's (2004) model, articulating the research production domain as "producer-push efforts," the research use domain as "user-pull efforts," and the research mediation domain as "linkage and exchange efforts."

\section{Justifying the Use of the KMb Matrix Tool}

Before providing an overview of the tool created by Qi and Levin (2013), I would like to present my justification for selecting this tool. I think the major potential critique of this study might be problematizing the use of website data to assess $\mathrm{KMb}$ efforts rather than a different methodology (e.g., in-depth case studies of educational organizations). First, I was interested in assessing the $\mathrm{KMb}$ efforts of a hundred organizations and case study work was not a feasible methodology due to the size of the sample. Similarly, one of the strengths of this tool is that it can be used to compare a wide range of diverse organizations across sectors, countries, and types of organizations. Scores arising from this tool have since been used to sample top performing organizations in relation to $\mathrm{KMb}$ for in-depth case studies, another use for the tool. To use this tool on a smaller subset of organizations, I argue that this tool should be utilized in conjunction with deeper qualitative methodology (such as case studies) in order to provide a comprehensive view of organizational $\mathrm{KMb}$ efforts. These choices, of course, depend on the goals of the research-and the goal of this study was to provide a broad overview of how a large number of organizations in the education sector compare in relation to $\mathrm{KMb}$ efforts, rather than provide a more thorough exploration of a few organizations. Second, in the current societal context websites are often a primary vehicle to promote organizational activities. Duffy (2000) notes: "the advantages of the medium over traditional communication formats in terms of flexibility, speed and reach make it an obvious route for research dissemination" (p.349). The recent demand to improve knowledge mobilization across public service sectors has been accompanied by an increased use of websites and various other technologies to facilitate dissemination efforts (Chavkin \& Chavkin, 2008). As a result, organizational websites have the potential to provide important insights in knowledge mobilization processes occurring across sectors. In addition to this fact, organizational websites often contain information that approximates face-to-face interactions. For instance, events listed on websites often have information about the types of stakeholders attending the event and the content of the event among other details. Similarly, websites often include information about networks of people working together on various projects or initiatives.

While recognizing and acknowledging the limitations of the tool I have chosen to use, I argue that virtually no tools exist to measure $\mathrm{KMb}$ efforts across organizations and using the baseline data from this tool is important first step in identifying which organizations should be considered for more in-depth analysis. The Social Sciences and Humanities Research Council (SSHRC) of Canada defines a research tool as: 
SSHRC defines research and related tools as vehicles that broadly facilitate research and related activities. Social science and humanities tools enable researchers to collect, organize, analyze, visualize, mobilize and store quantitative and qualitative data and creative outputs. Tools can be created as part of a research or related undertaking, or purchased off the shelf. (SSHRC, 2014)

This tool was created empirically from the evaluation of hundreds of different websites, prior to its application to the 105 I used in this study (for an overview of the first phase of the tool's development, please see Sá, Faubert, Edelstein, \& Qi, 2012). The other strength of the tool is that it provides a systematic approach — strategy by strategy and element by element - to look at diverse organizations in a uniform way. While many organizations might be engaged in activities not posted on their websites or have activities on their websites that they no longer engage in, I still argue that when attempting to assess a hundred diverse organizations in the area of KMb where little is known, this study and the use of this tool (while imperfect) still make an important contribution to understanding the relative efforts occurring across the system by universities, ministries, RBOs, and school districts. In summary, I believe the benefits of the tool outweigh the potential limitations of its use. Potential uses for the tool include the following:

- Specific organizations can use the tool to assess their KMb efforts in a systematic way across categories that the literature suggests increase research use and impact.

- Diverse organizations across a sector or between sectors can use the tool to draw comparisons between $\mathrm{KMb}$ efforts. This is important because we currently do not know what levels of $\mathrm{KMb}$ are occurring across the system (e.g., in universities, in ministries, by RBOs, or in school districts), and identifying the relative intensity of these efforts at different parts of the system can inform system-wide improvement initiatives (e.g., low levels of $\mathrm{KMb}$ in particular areas represent opportunities to ramp up efforts in a particular area).

- This tool provides baseline data on the types of $\mathrm{KMb}$ efforts led by different types of organizations; hence, organizations can use this data to benchmark their efforts.

- High scores in particular areas of the tool provide exemplary examples and a systematic way to choose cases for further research. For instance, organizations with high network ratings could provide case studies of exemplary practices that others could try to increase their impact in this area.

\section{An Overview of Qi and Levin's KMb Matrix Tool}

The $\mathrm{KMb}$ matrix tool (Figure 2) is a matrix that measures organizational research-dissemination strategies (e.g., research-based products, events, and networks) and research-use indicators as they relate to strategies (e.g., different types of strategies, ease of use, accessibility, and audience). The tool was informed by the literature and tested over a two-year period among the Research Supporting Practice in Education (RSPE) team at the University of Toronto (a team of researchers and graduate students) to decide on the various categories and point allotments. See Qi and Levin (2013) for more information on the tool development and Appendix A for details on the breakdown of each cell of the matrix. 


\begin{tabular}{|c|c|c|c|c|c|c|}
\hline \multicolumn{7}{|c|}{ Research Dissemination Strategies } \\
\hline \multirow{7}{*}{ 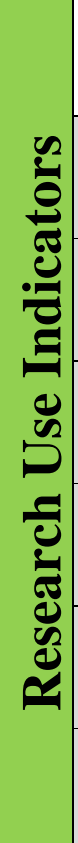 } & & Products & Events & Networks & $\begin{array}{l}\text { Balance, } \\
\text { Accessibility }\end{array}$ & $\begin{array}{l}\text { TOTAL } \\
\text { POINTS }\end{array}$ \\
\hline & $\begin{array}{l}\text { Different } \\
\text { Types }\end{array}$ & 3 points & 6 points & 6 points & 5 points & $\begin{array}{l}\text { /20 } \\
\text { points }\end{array}$ \\
\hline & Ease of Use & 2 points & 6 points & 2 points & 4 points & $\begin{array}{l}/ 14 \\
\text { points } \\
\end{array}$ \\
\hline & Accessibility & 3 points & 6 points & 4 points & 3 points & $\begin{array}{l}\text { /16 } \\
\text { points }\end{array}$ \\
\hline & $\begin{array}{l}\text { Audience } \\
\text { Focus }\end{array}$ & 4 points & 2 points & 4 points & N/A & $\begin{array}{l}110 \\
\text { points }\end{array}$ \\
\hline & $\begin{array}{l}\text { Collaborative, } \\
\text { Mission }\end{array}$ & N/A & N/A & 4 points & 8 points & $\begin{array}{l}\text { /12 } \\
\text { points }\end{array}$ \\
\hline & $\begin{array}{l}\text { TOTAL } \\
\text { POINTS }\end{array}$ & $/ 12$ & $/ 20$ & $/ 20$ & $/ 20$ & 172 \\
\hline
\end{tabular}

Figure 2. $\mathrm{KMb}$ matrix tool to evaluate $\mathrm{KMb}$ efforts using data from organizational websites (Adapted from Qi \& Levin, 2013).

\section{Method}

This study compares the $\mathrm{KMb}$ efforts of four types of organizations involved in the public education system: faculties of education $(N=21)$ where research is produced, ministries of education $(N=26)$ where decisions about K-12 education are made, school districts $(N=14)$ where educational research is applied, and $\operatorname{RBOs}(N=44)$ where the adaptation and translation of academic research for practical use are facilitated. Data was collected using the KMb tool from each organizational website. Data Analysis included descriptive statistics (e.g., frequencies, percent scores, means, and standard deviation), Cronbach's $\alpha$, and independent-samples KruskalWallis tests (pairwise comparisons were conducted where results were significant), using SPSS.

Reliability testing was conducted using Cronbach's $\alpha$ to determine whether each of the $\mathrm{KMb}$ indicator totals (e.g., types of strategies, ease of use, accessibility, audience focus, and other extra indicators) could be reliably aggregated as an overall indicator of KMb efforts. Cronbach's $\alpha$ results range from 0 (no reliability) to 1 (high reliability). The statistical literature indicates that a value of $0.7-0.8$ is an acceptable value for Chronbach's $\alpha$ (Field, 2005). Cronbach's $\alpha$ was calculated for the $\mathrm{KMb}$ indicators at .862 ; therefore, the five variable totals can be reliably combined into a $\mathrm{KMb}$ indicator total. The same reliability testing was conducted for $\mathrm{KMb}$ strategies (e.g., products, events, networks, and other strategies). Cronbach's $\alpha$ for KMb strategies was calculated at .828; therefore, the four strategy variable totals can be reliably combined into a $\mathrm{KMb}$ strategy total. 


\section{Findings: Comparing KMb Efforts Across the System}

This section reports on a comparison of $\mathrm{KMb}$ efforts of 105 educational organizations: faculties of education $(N=21)$, research brokering organizations $(N=44)$, school districts $(N=14)$, and ministries of education $(N=26)$. Across all organizations, the average score on the KMb matrix was $42 \%$. Disaggregated by type of organization, research brokering organizations had the highest average score $(M=56.0 \%)$, followed by faculties of education $(M=54.3 \%)$, school districts $(M=$ $30.4 \%)$, and ministries $(M=27.8 \%)$. Ministries are the most variable $(S D=13.2)$, followed by RBOs $(S D=12.3)$ and school districts $(S D=10.1)$, with universities having the lowest variability $(S D=6.6)$. An independent-samples Kruskal-Wallis test was conducted to evaluate differences among the four types of organizations-RBOs, faculties of education, school districts, and ministries - on KMb efforts. Non-parametric statistical tests were conducted because the data from the website tool are ordinal and not normally distributed. The test, which corrected for tied ranks, was significant, $\chi^{2}(3, N=105)=42.31,(p<.001)$; therefore, there are significant differences in $\mathrm{KMb}$ efforts among diverse kinds of organizations. Kruskal-Wallis tests do not analyze which groups are different, but only that differences exist; therefore, follow-up tests were conducted to evaluate pairwise differences among the four types of organizations. RBOs and faculties of education perform similarly; school districts and ministries perform similarly; and there are significant differences between these two groups, with RBOs and faculties of education having stronger $\mathrm{KMb}$ efforts. Although they provide information about significance, these tests do not calculate effect size. As a result, descriptive statistics and raw scores were used in Figure 3 to show the magnitude of the differences.

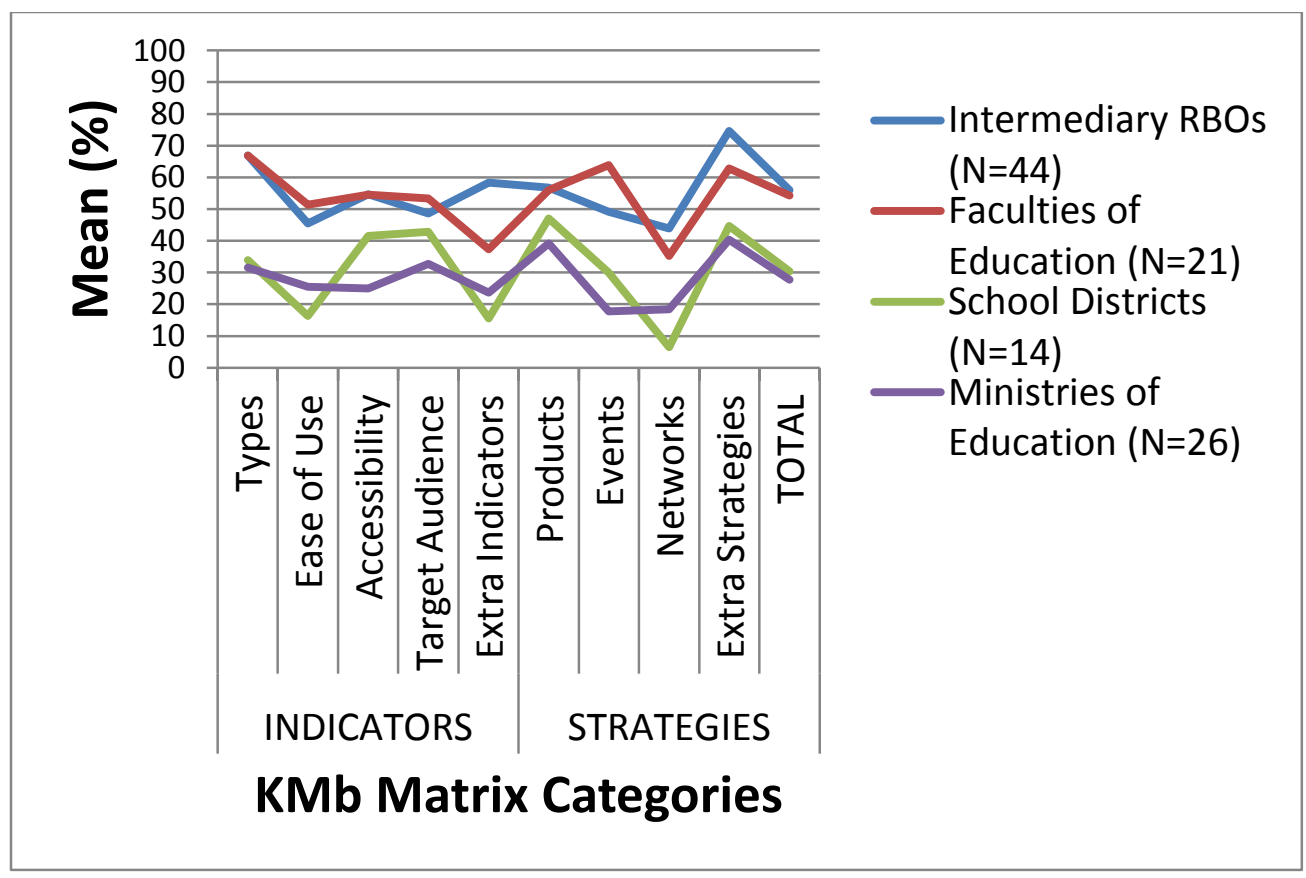

Figure 3. Comparison of KMb efforts of RBOs, faculties of education, school districts, and ministries of education. 
RBOs and faculties of education perform similarly and score highest on KMb efforts while school districts and ministries perform similarly, scoring lower on KMb efforts; however, there are modest levels of $\mathrm{KMb}$ across organizations. With the exception of faculties of education, which scored best on the KMb events strategy, all of the organizations fared best at products followed by events; networks being the weakest of the KMb efforts. Scores on products and events were often much higher than scores on networks (twice as high in ministries of education, seven times higher in school districts, and one-and-a-half times higher in faculties of education). Faculties of education had the highest score on $\mathrm{KMb}$ events, with many research events, talks, and lectures listed on their websites. It is a common misconception that academic events, which allow researchers to push out their work by simply telling people about their research, will increase research use. The literature, however, suggests that much more active and interactive forms of research exchange are necessary if research is to be incorporated into daily practice by teachers and policymakers in a meaningful way (Nutley et al., 2007).

All four kinds of organizations scored the lowest on utilizing networks as a KMb strategy (although faculties and RBOs did better than school districts and ministries). Network strategies were assessed in relation to the diversity of existing network types and the frequency of activity and interaction within each network were assessed. Organizations that had a high score in this category circulated research-related e-bulletins to their networks, an example of a "producer push" strategy. RBOs score highest on network activities and interactions, with scores on average almost $10 \%$ higher than faculties of education. RBOs often had diverse membership composition and range of various stakeholders. In most cases, the primary role of RBOs was networking among diverse organizations and groups. Very few organizations, including RBOs, had features on their websites that would allow two-way communication (exceptions to this are found in some RBOs: Canada Education Association, Research Impact from York University, People for Education, and The Learning Partnership). Even where interactive features were available on websites, there were usually low levels of actual activity (the only exception to this was People for Education, which included an active online forum and network of parents across the province).

Another area where faculties of education, school districts, and ministries fared poorly was in the collaborative category, which contained ratings for the collaborative nature of the network and also evaluated the mission statement of these organizations in relation to $\mathrm{KMb}$. One area where school districts scored more closely to faculties of education and RBOs - and better than ministries - was audience focus for their $\mathrm{KMb}$ products, events, and networks. School districts often had resources tailored for teachers, students, and parents. This may be due to the increased emphasis on differentiated instruction and meeting the needs of diverse populations in education, which may have contributed to targeting their $\mathrm{KMb}$ efforts to the specific needs of different stakeholder groups.

Most organizations had fairly low scores on KMb efforts. Figure 4 shows a histogram of total scores by type of organization. 


\section{Total Scores on KMb Efforts by Type of Organization}

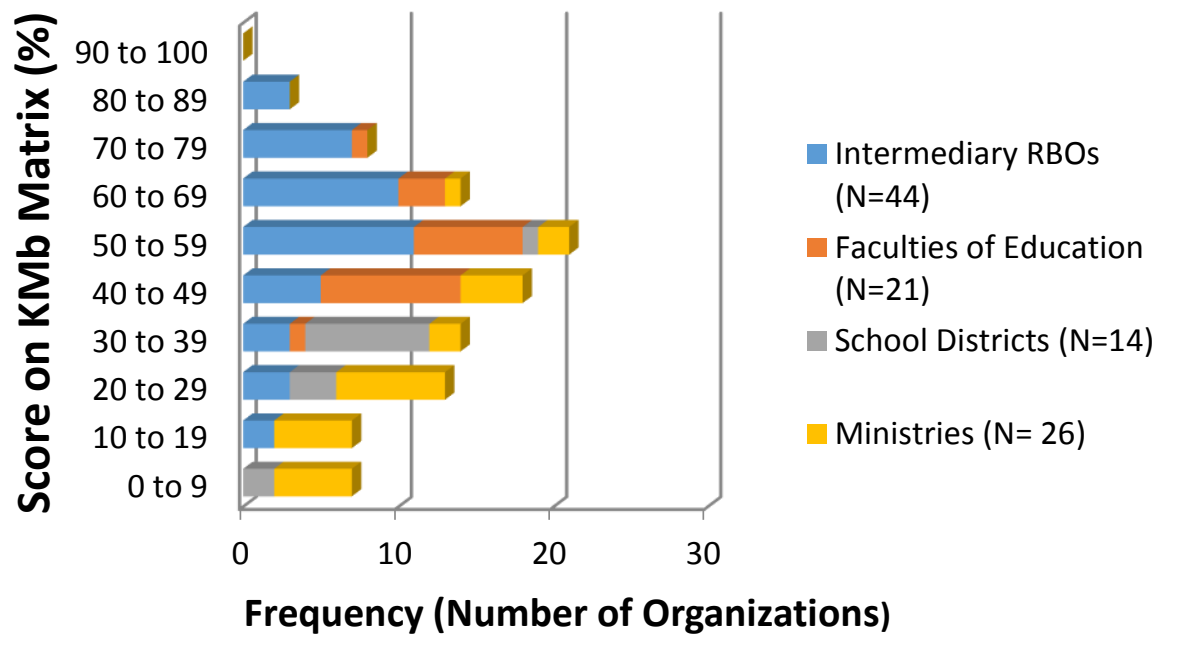

Figure 4. Histogram of total scores on $\mathrm{KMb}$ efforts by organizational type.

Seventy-six percent of the organizations (80/105) scored less than $60 \%$ on the evaluative matrix. RBOs tended to score highest on the matrix, with 20 out of the 25 top organizations being RBOs.

\section{Discussion and Implications}

Research producers (faculties of education) and RBOs tend to be more engaged in KMb efforts than research users (ministries and school districts). Findings from this study suggest low levels of $\mathrm{KMb}$ efforts in school districts and ministries. The efforts of faculties of education and RBOs are moderate, with some organizations being extensively engaged in these efforts. Of the 13 organizations out of 105 that scored between $70 \%$ and $90 \%$ on their KMb efforts, 12 (92\%) were RBOs; so, the top-performing organizations in terms of $\mathrm{KMb}$ efforts are RBOs. A potential explanation for this trend has to do with the priorities and focus of the different kinds of organizations. The primary focus of faculties of education is research; as a result, research and its dissemination is an important part of how universities function. Increasing the profile of research in society is important for faculties because it galvanizes the government funding and societal support necessary to keep operating. Given this reality, it is surprising that faculties of education still only score moderately on KMb efforts because research and its importance have perhaps been longer on their radar than on the radars of other kinds of organizations. It is difficult on most university websites even to ascertain what research is being done by whom (Sá et al., 2011), let alone what the implications of that research might be for sector stakeholders that might apply that knowledge.

Organizations such as ministries and school districts have not articulated their research priorities until recently; hence, their low levels of KMb efforts are not surprising and are consistent with the literature (Cooper \& Levin, 2010; Nutley et al., 2007). These kinds of would-be user 
organizations focus on teaching, learning, and student outcomes. Only in the past few decades has the discussion about how to improve public services begun to revolve around evidence-informed decision making to support policies and practice. Despite the growing awareness of the need for research to better inform service delivery in the health and education sectors, these linkages are still far from explicit. This is true for a multitude of reasons: a lack of understanding of how to build these linkages, a lack of skills and capacity to do KMb work at the practitioner level (although this should not be construed as a lack of competence, intelligence, or willingness to do so on the part of frontline practitioners), and a lack of organizational and system-level processes to facilitate systematic $\mathrm{KMb}$ efforts across a large number of organizations and professionals.

RBOs focus explicitly on efforts to connect research to practice, so it is not surprising that the majority of the top-performing organizations in $\mathrm{KMb}$ are these organizations that have explicit mandates in relation to connecting research producers to research users. Strategies used by RBOs are not always consistent with the growing evidence on effective KMb strategies; often, passive strategies are being utilized such as creating and posting research summaries online rather than investing in long-term substantive network efforts. Explanations for this might include the cost and resources required to build and sustain networks rather than the one time investment of creating a product or hosting an event. Although there might not be extensive empirical evidence on $\mathrm{KMb}$, what does exist is largely ignored, as shown by the focus on passive strategies such as posting research-based products on websites rather than investing in multi-stakeholder network strategies. Studies have shown fairly clearly since the 1960s that passive strategies are not effective and that when the content is focused and relevant, events and networks are more powerful change mechanisms; however, in the new age of Internet communication, organizations tend to spend most of their time creating research products and posting them online - a passive strategy that is unlikely to increase uptake (for some data on the uptake of online research, please see Edelstein, Shah, \& Levin, 2012).

It should also be noted that a potential limitation of this study has to do with assessing and designating $\mathrm{KMb}$ efforts as low, moderate, or extensive. This study is the first to analyze baseline data from different organizations in education on their levels of KMb efforts. Only with time and more empirical data, a better understanding of appropriate $\mathrm{KMb}$ activity benchmarks for different kinds of producers, users, and RBOs will emerge. The KMb matrix tool provides an approach to measuring and comparing $\mathrm{KMb}$ efforts across diverse organizations, addressing the need for tools lamented throughout the literature. Other kinds of ratings are certainly possible. The need to develop tools to measure research use as well as KMb efforts and processes is commonly discussed across sectors (Lavis et al., 2006; Mitton, Adair, McKenzie, Patten, \& Perry, 2006; Nutley et al., 2007). Although this matrix might seem crude, it is still one of the first tools to begin exploring how research dissemination efforts of diverse educational organizations compare. This tool can also be used by organizations to assess and think through their KMb efforts. As stated earlier, online data often mirror interaction occurring face-to-face in the real world; hence, these data can provide an estimate of actual levels of $\mathrm{KMb}$ activity. For this study, although not reported in this article, the KMb matrix was adapted to include space for providing written descriptions of each element of the matrix in addition to a point score. The written analysis of each organization contained descriptions of the kinds of resources found on the website, the major themes addressed, and interesting $\mathrm{KMb}$ practices and networks. As a result, this tool is not simply a way to compare organizations quantitatively, but it provides a systematic approach to examine each organization in a consistent way. 
The ultimate aim of the tool is to provide data to guide more focused investigations of the various partnerships, events, and products uncovered by the application of the $\mathrm{KMb}$ matrix to further investigate how these $\mathrm{KMb}$ strategies influence research use in education. The descriptive comments in the matrix, in conjunction with the quantitative assessment, provide organizations with ideas for how they might improve their communication of research using their website. Also, this study yields some examples of organizations doing well in various areas. The tool can be used to learn from organizations that score high in areas - for instance, exploring the organizations that score the best in the networks strategy might yield ideas and resources for other institutions to utilize in their $\mathrm{KMb}$ efforts.

This approach, as a way of mapping and comparing activity across a number of organizations, could be a first research phase in a variety of contexts, including schools, districts, ministries, and faculties of education. Using a website analysis for initial data collection provides the data necessary to construct detailed organizational profiles that can guide the development of more focused survey and interview instruments. This approach also reduced potential response bias; for instance, websites and annual reports provide more reliable data than that collected via self-reporting mechanisms such as asking individuals about the scope, resources, and staffing of their institution.

\section{Conclusion}

The field of $\mathrm{KMb}$ in Canadian education, as well as globally, is still in its infancy for the following reasons: (a) the modest levels of $\mathrm{KMb}$ efforts occurring across sectors, (b) the obscurity surrounding the various roles that different organizations can or should play, and (c) the lack of empirical work in virtually all areas. This is especially true regarding the lack of methodological approaches and tools to gauge KMb efforts and its impact. To move the field forward, development of methodological tools is necessary-alongside replication studies in which tools that do exist are widely applied and tested - to accumulate reliable bodies of evidence that can inform the field of knowledge mobilization in Canada and internationally. 


\section{References}

Brown, C. (2015). Leading the use of research and evidence in schools. London, England: Institute of Education Press.

Burns, T., \& Schuller, T. (Eds.). (2007). The evidence agenda, In T, Burns and T. Schuller (Eds.), OECD, Evidence in Education: Linking Research and Policy (pp. 15-30). Paris, France: Centre for Educational Research and Innovation.

Chavkin, N., \& Chavkin, A. (2008). Promising website practices for dissemination research on family-school partnerships to the community. The School Community Journal, 18(1), 7992.

Coburn, C., \& Stein, M. K. (Eds.). (2010). Research and practice in education: Building alliances, bridging the divide. Toronto, ON: Rowman \& Littlefield.

Cooper, A. (2014a). Knowledge mobilization intermediaries in education: A cross-case analysis of 44 Canadian organizations. Evidence \& Policy, 10(1), 29-59.

Cooper, A. (2014b). The Use of Online Strategies and Social Media for Research Dissemination in Education. Education Policy Analysis Archives, 22(70), 1-27. Available at http://epaa.asu.edu/ojs/article/download/1369/1342

Cooper, A. (2013). Research mediation in education : A typology of research brokering organizations that exist across Canada. Alberta Journal of Educational Research, 59(2), 181-207.

Cooper, A., \& Levin, B. (2010). Some Canadian contributions to understanding knowledge mobilization. Evidence and Policy, 6(3), 351-369.

Cooper, A., \& Levin, B. (2013). Research use by leaders in Canadian school districts. International Journal of Education Policy and Leadership, 8(7), 1-15.

Cordingley, P. (2008). Research and evidence-informed practice: Focusing on practice and practitioners. Cambridge Journal of Education, 38(1), 37-52.

Duffy, M. (2000). The Internet as a research and dissemination resource. Health Promotion International, 15(4), 349-353.

Edelstein, H., Shah, S., \& Levin, B. (2012). Mining for data: Assessing the use of online research. International Journal of Humanities and Social Science, 2(9), 1-12.

Field, A. (2005). Discovering statistics using SPSS (2 ${ }^{\text {nd }}$ Ed.). London: Sage Publications Ltd.

Finnigan, K., \& Daly, A. (Eds.). (2014). Using research evidence in education: From the schoolhouse door to Capitol Hill. New York, NY: Springer.

Landry, R., Amara, N., \& Lamary, M. (2001). Utilization of social science research knowledge in Canada. Res Policy, 30, 333-349.

Lavis, J., Lomas, J., Hamid, M., \& Sewankambo, N. K. (2006). Assessing country-level efforts to link research to action. Bulletin of the World Health Organization, 84(8), 620-628.

Levin, B. (2004). Making research matter more. Education Policy Analysis Archives, 12 (56). Retrieved from http://epaa.asu.edu/epaa/v12n56/

Brock Education Journal, 25 (1), Fall 2015 
Meyer, M. (2010). The rise of the knowledge broker. Science Communication, 32(1), 118-127.

Mitton, C., Adair, C. E., McKenzie, E., Patten, S. B., \& Perry, B. W. (2007). Knowledge transfer and exchange: Review and synthesis of the literature. The Milbank Quarterly, 85(4), 729768.

Nutley, S., Walter, I., \& Davies, H. (2007). Using evidence: How research can inform public services. Bristol: Policy Press.

Qi, J. \& Levin, B. (2013). Assessing organizational efforts to mobilize research knowledge in education. Education Policy Analysis Archives, 21(2), 1- 24.

Sá, C., Faubert, B., Edelstein, H., \& Qi, J. (2012). Understanding how organisations use the internet to mobilise knowledge: Findings from the field of education. International Journal of Management in Education, 6(1/2), 1-21.

Sá, C., Li, S. \& Faubert, B. (2011). Faculties of education and institutional strategies for knowledge mobilization: An exploratory study. Higher Education, 61(4), 501-512.

Social Sciences and Humanities Research Council (SSHRC) of Canada (2014). Guidelines for Support of Tools for Research and Related Activities. Retrieved May 24, 2016, from http://www.sshrc-crsh.gc.ca/funding-financement/policiespolitiques/support_tools_soutien_outils-eng.aspx

Tetroe, J., Graham, I., Foy, R., Robinson, N., Eccles, M., Wensing, M., Durieux, F., Neilson, C., Adily, A., Ward, J., Porter, C., Shea, B. \& Grimshaw, J. (2008). Health research funding agencies support and promotion of knowledge translation: An international study. The Milbank Quarterly, 86(1), 125-155.

Wilson, P., Petticrew, M., Calnan, M.W., \& Nazareth, I. (2010). Does dissemination extend beyond publication: A survey of a cross section of public funded research in the UK. Implementation Science, 5(61), 1-8. 
Appendix A: Matrix to Evaluate KMb Practices of Organizations Using Website Analysis

\begin{tabular}{|c|c|c|c|c|c|}
\hline $\begin{array}{l}\text { Strategies \& } \\
\text { Indicators }\end{array}$ & Products & Events & Networks & Balance, Accessibility & Total \\
\hline $\begin{array}{l}\text { Different } \\
\text { types }\end{array}$ & $\begin{array}{l}1 \text { point ( } 1-2 \text { types }) \\
2 \text { points }(3-4 \text { types }) \\
3 \text { points }(5-6 \text { types })\end{array}$ & $\begin{array}{l}2 \text { points }(1-2 \text { types }) \\
4 \text { points }(3-4 \text { types }) \\
6 \text { points }(5-6 \text { types })\end{array}$ & $\begin{array}{l}2 \text { points ( } 1 \text { type }) \\
4 \text { points ( } 2 \text { types) } \\
6 \text { points ( } 3 \text { types })\end{array}$ & $\begin{array}{l}1 \text { point ( } 1 \text { strategy); } 2 \text { points ( } 2 \\
\text { strategies); } 3 \text { points ( } 2 \text { strategies } \\
\text { with a good balance }) ; 4 \text { points } \\
\text { (three strategies); } 5 \text { points (three } \\
\text { strategies with a good balance) }\end{array}$ & $/ 20$ \\
\hline Ease of use & $\begin{array}{l}1 \text { point (means provided to } \\
\text { make comment on the main } \\
\text { page) } \\
2 \text { points (means provided to } \\
\text { make comments on specific } \\
\text { products) }\end{array}$ & $\begin{array}{ll}2 \text { points } & 2 \text { points } \\
\text { (occasional } & \text { (events } \\
\text { follow-ups) } & \text { archived) } \\
4 \text { points (regular } & \\
\text { follow-ups) } & \end{array}$ & $\begin{array}{l}2 \text { points (archived network } \\
\text { communication ) }\end{array}$ & $\begin{array}{l}1 \text { point ( } 1 \text { searching tool) } \\
2 \text { points ( } 2 \text { searching tools) } \\
3 \text { points ( } 3 \text { searching tools) } \\
4 \text { points (4 searching tools) }\end{array}$ & $/ 14$ \\
\hline Accessibility & $\begin{array}{l}1 \text { point (small portion) } \\
2 \text { points (large portion) } \\
3 \text { points (all) }\end{array}$ & $\begin{array}{l}2 \text { points (conditions attached) } \\
4 \text { points (part of events with } \\
\text { conditions attached) } \\
6 \text { points (no conditions } \\
\text { attached) }\end{array}$ & $\begin{array}{l}2 \text { points (once every } 3 \\
\text { months or less) } \\
4 \text { points (more frequently) }\end{array}$ & $\begin{array}{l}1 \text { point (low readability) } \\
2 \text { points (average readability) } \\
3 \text { points (high readability) }\end{array}$ & $/ 16$ \\
\hline $\begin{array}{l}\text { Focus of } \\
\text { audience }\end{array}$ & $\begin{array}{l}1 \text { point (part of products) } \\
2 \text { points (part of products } \\
\text { with clear application } \\
\text { information) } \\
3 \text { points (all products) } \\
4 \text { points (all products with } \\
\text { clear application information) }\end{array}$ & 2 points (brief introduction) & $\begin{array}{l}2 \text { points (general } \\
\text { introduction about who is } \\
\text { involved in the network) } \\
4 \text { points (clear introduction } \\
\text { about purpose, who is } \\
\text { involved, and the } \\
\text { contributions) }\end{array}$ & & $/ 10$ \\
\hline $\begin{array}{l}\text { Collaborative } \\
\text { nature of } \\
\text { network; } \\
\text { mission } \\
\text { statement }\end{array}$ & & & $\begin{array}{l}\text { Collaborative nature of } \\
\text { the network } \\
2 \text { points (some indication) } \\
4 \text { points (strong indication) }\end{array}$ & $\begin{array}{l}\text { Explicit KMb statement on the } \\
\text { site } \\
2 \text { points (general statement ); } \\
4 \text { points (clear statement without } \\
\text { overall plan); } \\
6 \text { points (strong statement loosely } \\
\text { connected to org. overall plan); } \\
8 \text { points (strong directly connected } \\
\text { to org. plan) }\end{array}$ & $/ 12$ \\
\hline Total Points & $/ 12$ & $/ 20$ & $/ 20$ & $/ 20$ & $/ 72$ \\
\hline
\end{tabular}

